\title{
Travails of an Obstetrician and Gynaecologist in the Periphery: Rights vs Responsibilities
}

\author{
CD Ekanayake
}

Travails may be defined as efforts or struggles that often involve hard work. These, be it favourable or not are often not adequately addressed in published literature as these may not be recognized to be of academic significance and linked to quality of care, though one of the objectives of such published literature is to improve quality of care. If quality of care is actually the benchmark, these experiences or situations are of some significance as these issues, we grapple with day-in day-out, eventually affect the services we provide. Furthermore these experiences or situations may have an effect on the rights of patients and responsibilities of the consultant. In such situations it may be necessary to balance rights versus responsibilities. It is in this light that I wish to discuss some issues linked to the experiences of an obstetrician and gynaecologist in the periphery.

\section{Local challenges}

More often than not a qualified public official is received with honour and respect by the local community which in return makes the professional think that he or she must do something to improve the services. However the limitations in facilities sometimes puts a lid on the level of care that we want to deliver. You can either not do much; try to do something; or try to improve while doing what's possible. Although we all start off with the latter, reality is that we eventually end up in the middle category. Logistical limitations include financial limitations, manpower issues, and sometimes albeit rarely, undercutting by some of our own peers. Perhaps we are trained all too well in clinical medicine but with very little experience in entrepreneurship. Traits such as creativity, perseverance and social skills, often determine the success of the project more than your technical expertise. Success in one often leads to many others and can be very fulfilling in terms of job satisfaction.

Working abroad is akin to something like cleaning a vase, which is what is expected of you, whereas here it is not clearly defined and is like you are given a piece of clay which you can mould in to anything. Hypothetically the piece of clay may remain the same or can be moulded to something even greater than a vase. Though the system equally rewards the person who does nothing and the one who tries to mould the piece of clay, people actually identify the sincerity and gladly accept whatever extra that is done by the professional.

Sri Lanka Journal of Obstetrics and Gynaecology

2018; 40: 49-50

DOI: http://doi.org/10.4038/sljog.v40i2.7847

\footnotetext{
${ }^{a}$ Senior Lecturer, Department of Obstetrics and Gynaecology, Faculty of Medicine, General Sir John Kotelawala Defence University, Ratmalana, Sri Lanka.
}

Correspondence: CE, e-mail: <cdekanayake2000@yahoo.co.uk>

(D) $h t t p: / / o r c i d . o r g / 0000-0001-5662-155 \mathrm{X}$

Competing interest: The authors report no conflict of interest 


\section{The Line Ministry}

This account would not be complete if nothing were to be said about the Ministry of Health. Whilst Sri Lanka has made giant strides in healthcare, largely due to the political will and the commitment of the Ministry to provide free health, there is certainly much more to be done, which must be done a lot more efficiently. We all need to realize that free health is a misnomer in this country; even the patients know otherwise, it is only the foreigners who think that free health exists.

If we are to achieve western standards for health care indicators from the current medium gains, our main challenges will be productivity and accountability, which should be addressed firstly by the ministry itself. If productivity were the benchmark the best estimate of that would be the queue of specialists seated on benches to obtain placements.

The culture that the clinician is solely responsible for patient well-being should change to a system driven collective responsibility like the NHS if accountability is to be addressed in a manner that befits the 21 st century ${ }^{1,2}$.

\section{Basic amenities and travelling}

The country has progressed so much that except a few outposts most places have all the basic amenities including recreational facilities. It is the travel on 'killer roads' that remains a challenge. The productivity loss would be staggering if a highly skilled professional were to meet with an accident, not to mention the cost that the state accrued for his or her training. This is in addition to the emotional loss for immediate kith and kin. The questions that immediately come in to my mind are; was there actually no better way of overcoming this problem? Could we have done better which would have even improved the service delivery itself? Should people who serve in the periphery be given a special allowance?

\section{Social duty}

All of us succeed in our social responsibility in terms of working harmoniously with everyone, disbarring caste, status or religion, which actually plays a bigger part than all the misinformation fed by media. As public officials we also need to be mindful of the obligation of duty placed on us, and that respective strides in each of our fields will eventually drive the collective development of the country. As our children will eventually inherit the merits or demerits of our actions, we will fail by them if we do not do justice to the task at hand. We cannot always blame the politicians for all our problems perhaps we could have done better had we been better informed.

\section{Conclusion}

A key right of the patient, enshrined by a code of ethics, is to have access to best of care for which the service provider is duty bound. What about the issues faced by the service provider who is a junior consultant? Effects of which may in fact affect the service delivery itself. I have tried to broadly highlight some issues and differentiate among them as to what is our right and what is our responsibility. Something to ponder on!

\section{References}

1. Wachter RM. Personal accountability in healthcare: Searching for the right balance. BMJ Qual Saf. 2013; 22(2): 176-80.

2. Maybin J, Addicott R, Dixon A, Storey J. Accountability in the NHS: Implications of the Government's Reform Programme. 2011; 1-64. Available from: http://www.kingsfund.org.uk/ publications/index.html (Accessed on 25th March 2018). 